\title{
Total Irregular Labelling Of Butterfly and Beneš Network 5-Dimension
}

\section{Nilai Total Ketidakteraturan Butterfly dan Beneš Network 5-Dimensi}

\author{
Edy Saputra ${ }^{1 *}$, Nurdin $^{2}$, Supri Amir ${ }^{3}$
}

\begin{abstract}
This paper aims to determine the total vertex irregularity strength and total edge irregularity strength of Butterfly and Beneš Network 5-Dimension. The determination of the total vertex irregularity strength and the edge irregularity strength was conducted by determining the lower bound and upper bound. The lower bound was analyzed based on characteristics of the graph and other proponent theorems, while upper bound was analyzed by constructing the function of the irregular total labeling. The result show that the total vertex irregularity strength of Butterfly Network $\operatorname{tvs}(B F(5))=39$, the total edge irregularity strength $\operatorname{tes}(F B(5))=108$. The total vertex irregularity strength of Beneš Network tvs $(B B(5))=$ 71 , the total edge irregularity strength $\operatorname{tes}(B B(5))=214$.
\end{abstract}

Keywords: Butterfly, network, Beneš Network, total edge irregularity strength, total edge irregularity strength.

\begin{abstract}
Abstrak
Penelitian ini bertujuan menentukan nilai total tidak teratur titik dan sisi pada Butterfly dan Beneš Network 5-Dimensi. Penentuan nilai total ketidakteraturan titik dan sisi dilakukan dengan menentukan batas bawah terbesar dan batas atas terkecil. Batas bawah dianalisis berdasarkan sifat-sifat graf dan teorema pendukung lainnya, sedangkan batas atas dianalisis dengan mengkonstruksi fungsi pelabelan total tidak teratur pada Butterfly dan Beneš Network. Berdasarkan hasil penelitian diperoleh nilai total tidak teratur titik untuk Butterfly Network $\operatorname{tvs}(B F(5))=39$ dan tes $(B B(5))=108$. Untuk Beneš Network nilai total tidak teratur titik adalah $\operatorname{tvs}(B F(5))=71$ dan $\operatorname{tes}(B B(5))=214$.
\end{abstract}

Kata kunci: Butterfly, network, Beneš Network, nilai total tidak teratur titik, nilai total tidak teratur sisi.

\section{PENDAHULUAN}

Sebuah sistem dapat didefinisikan sebagai koleksi dari beberapa objek, yang disebut komponen, yang terhubung dan memiliki tujuan. Seperti sistem komputer, beberapa sistem prosesor, jaringan komputer, sirkuit elektronik, sistem komunikasi, sistem pipa dan sistem

\footnotetext{
* Departemen Matematika, Universitas Hasanuddin

Email: ${ }^{1}$ edysaputra525@yahoo.co.id, ${ }^{2}$ nurdin1701@unhas.ac.id, ${ }^{3}$ supriamir88@gmail.com
} 


\section{Edy Saputra, Nurdin, Supri Amir}

transportasi. Jaringan interkoneksi adalah suatu skema yang menghubungkan unit multiprocessing sebuah sistem. Dimana jaringan interkoneksi memainkan peran sentral dalam menentukan kinerja keseluruhan dari sistem multicomputer. Jaringan interkoneksi memainkan peran penting untuk arsitektur paralel komputer dan PC-Cluster atau Jaringan Workstation. Sebuah jaringan interkoneksi dapat dimodelkan sebagai suatu graf dimana simpul/titik mewakili elemen pengolahan dan sisi mewakili saluran komunikasi antara elemen pengolahan. Graf seperti itu disebut struktur topologi jaringan interkoneksi.

Pelabelan graf didefinisikan sebagai pemberian label bilangan bulat tak negatif $\left(Z^{+}\right)$pada titik atau sisi atau keduanya dengan memenuhi aturan-aturan tertentu. Konsep pelabelan tidak teratur pada suatu graf pertama kali diperkenalkan oleh Chartrand dkk. [3]. Pelabelan tidak teratur pada graf $G$ didefinisikan sebagai suatu pemetaan yang memetakan himpunan sisi dari $G$ ke himpunan bilangan $\{1,2, \ldots, k\}$ sedemikian sehingga semua titik mempunyai bobot yang berbeda. Pada tahun 2007, Bača dkk [2] memperkenalkan pelabelan tidak teratur lainnya yang didasarkan pada pelabelan total, yaitu pelabelan total tidak teratur sisi dan pelabelan total tidak teratur titik. Bača dkk [2], misalkan $G=(V, E)$ adalah suatu graf. Fungsi $\alpha: V \cup E \rightarrow\{1,2, \cdots, c\}$ disebut pelabelan- $c$ total tidak teratur titik pada $G$, jika untuk setiap $x, u \in V$ dengan $x \neq u$, berlaku $w t(x)=\alpha(x)+\sum_{x y \in E} \alpha(x y) \neq w t(u)=\alpha(u)+\sum_{u v \in E} \alpha(u v)$. Nilai total ketidakteraturan titik dari $G$, dinotasikan dengan $\operatorname{tvs}(G)$, adalah bilangan bulat positif terkecil $c$ sedemikian sehingga $G$ mempunyai suatu pelabelan- $c$ total tidak teratur titik. Fungsi $\alpha: V \cup E \rightarrow\{1,2, \cdots, c\}$ disebut pelabelan- $c$ total tidak teratur sisi pada $G$, jika untuk setiap $x, u \in V$ dengan $x \neq u$, berlaku $w t(x)=\alpha(x)+\alpha(x y)+\alpha(y) \neq \alpha(u)+\alpha(u v)+\alpha(v)$. Nilai total ketidakteraturan sisi dari $G$, dinotasikan dengan tes $(G)$, adalah bilangan bulat positif terkecil $c$ sedemikian sehingga $G$ mempunyai suatu pelabelan- $c$ total tidak teratur sisi.

Penentuan nilai total ketidakteraturan titik dan sisi dari semua graf belum dapat dilakukan secara lengkap. Sampai saat ini hanya beberapa kelas graf yang sudah diketahui nilai total ketidakteraturan titik dan sisinya. Dalam survei Gallian [4] beberapa ahli telah menentukan nilai total ketidakteraturan titik dari beberapa graf. Bača dkk [2] memberikan batas atas dan batas bawah dari sebarang graf $G,\left[\frac{|E|+2}{3}|\leq \operatorname{tes}(G) \leq| E \mid\right.$. Kemudian Nurdin dkk [6] misalkan $G$ adalah suatu graf yang mempunyai $n_{i}$ titik berderajat $i$ dengan $i=\delta, \delta+1, \delta+2, \ldots, \Delta$ dengan $\delta$ dan $\Delta$ adalah derajat mimimum dan maksimum titik dari $G$, maka $\operatorname{tvs}(G) \geq \operatorname{maks}\left\{\left\lceil\frac{\delta+n_{\delta}}{\delta+1}\right],\left\lceil\frac{\delta+n_{\delta}+n_{\delta+1}}{\delta+2}\right\rceil, \ldots,\left\lceil\frac{\delta+\sum_{i=\delta}^{\Delta} n_{i}}{\Delta+1}\right\rceil\right\}$. Ahtsham dkk [1] telah menentukan nilai total ketidakteraturan titik graf Grid, yaitu $\operatorname{tvs}\left(P_{n}\right.$ ? $\left.P_{n}\right)=\left\lceil\frac{(m n+2)}{5}\right\rceil$ untuk $5 \leq m \leq 10$ dan $n \geq$ $m$.

Hingga saat ini pemanfaatan teori pelabelan graf dapat diaplikasikan dalam berbagai bidang, seperti sinar-X, analisis Kristalografi dan mendesain sistem jaringan komunikasi dan sebagainya. Jaringan Interkoneksi adalah skema koneksi dari sistem multiprosesing. Jaringan Interkoneksi dapat dimodelkan menjadi sebuah graf dimana titiknya mewakili proses elemen dan sisi mewakili komunikasi antara saluran. Jenis jaringan interkoneksi adalah Butterfly Network dan Beneš Network. Rajasingh dkk [8] telah menentukan tes untuk Butterfly Network dan Beně́ network. Nurdin [7] juga telah menemukan nilai ketidakteraturan Butterfly Network level 2. Marzuki dkk [5] menemukan Nilai Total Ketakteraturan Dari Graf Butterfly Network Level 3. Pada Penelitian ini dikaji sifat-sifat, karakteristik dan menentukan nilai ketidakteraturan titik dan sisi pada butterfly network dan Beneš Network 5-dimensi dimana berkaitan dengan Acces Control pada jaringan. 


\section{Edy Saputra, Nurdin, Supri Amir}

Definisi 1.1. Himpunan titik $V$ dari $r$-dimensi Butterfly $B F(r)$ adalah himpunan pasangan $[t, i]$, dengan $i$ adalah dimensi atau tingkat titik $(0 \leq i \leq r)$ dan $t$ adalah $r$-bit bilangan biner yang menunjukkan baris titik. Dua titik $[t, i]$ dan $\left[t^{\prime}, i^{\prime}\right]$ dihubungkan oleh sisi jika memenuhi salah satu dari:

i) $t$ dan $t^{\prime}$ adalah identik,(sisi lurus) dan $\left|i^{\prime}-i\right|=1$ atau

ii) $t$ dan $t^{\prime}$ berbeda hanya pada bit ke-i'. (sisi silang/cross) dan $i^{\prime}=i+1$.

Suatu Butterly network $B F(r)$ dengan $r$-dimensi memiliki $(r+1) 2^{r}$ titik dan $r 2^{r+1}$ sisi. Gambar 1.1(a) adalah bentuk normal BF(2) dan Gambar 1.1(b) adalah isomorfisma dari BF(2) yang disebut bentuk diamond dari Butterfly network.
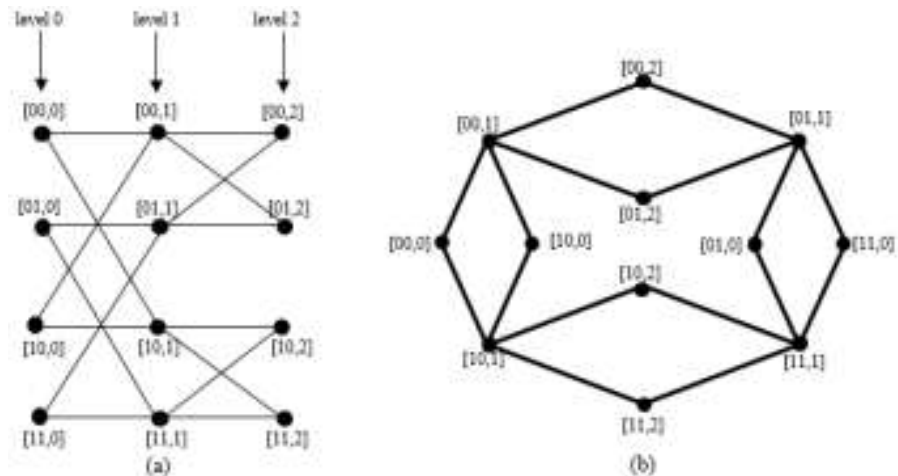

(b)

Gambar 1.1 Butterly network $B F(2)$ dan isomorfismanya

Definisi 1.2. Beneš network memiliki $2 r+1$ dimensi dengan $2^{r}$ titik pada setiap tingkat. dimensi 0 sampai $r$ merupakan $r$-dimensi butterfy network kemudian tingkat $r$ sampai $2 r+1$ merupakan $r$-dimensi butterfy network yang terbalik. Jadi r-dimensi beneš network memiliki $(2 r+1) 2^{r}$ titik dan $r 2^{r+2}$ sisi, dinotasikan dengan $B B(r)$.

Pada Gambar 1.2: (a) adalah bentuk normal $B F(2)$, (b) adalah bentuk normal $B F(2)$ dan (c) adalah isomorfisma dari $B B(2)$ yang disebut bentuk diamond dari Beneš network.

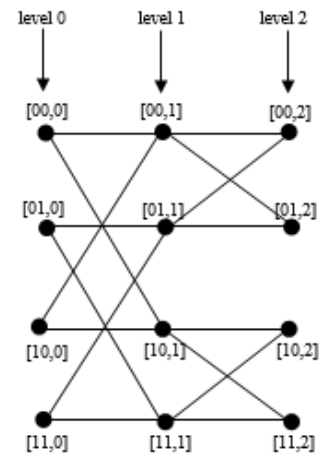

(a)

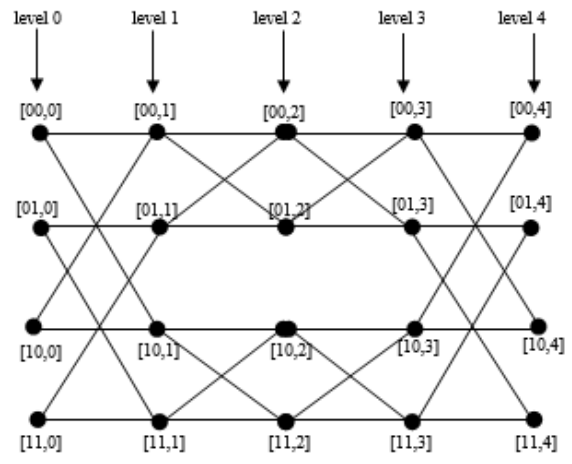

(b)

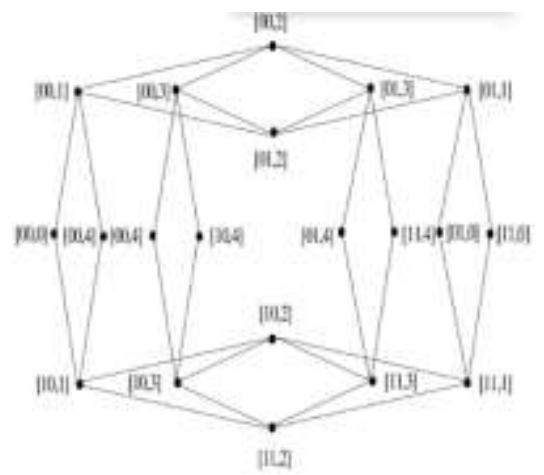

112

Gambar 1.2. Butterfly network $B f(2)$, Beneš network $B B(2)$ dan isomorfismanya 


\section{Edy Saputra, Nurdin, Supri Amir}

\section{HASIL DAN PEMBAHASAN}

Untuk menentukan nilai tvs dan tes dilakukan dengan menentukan batas atas terkecil dan batas bawah terbesar. Dalam menentukan batas bawah terbesar dianalisis berdasarkan sifat-sifat dan karakteristik graf, banyaknya derajat titik, banyaknya titik serta teorema pendukung. Sedangkan dalam menentukan batas atas terkecil dilakukan konstruksi fungsi pelabelan total tidak teratur untuk butterfly network dan Beneš network.

Teorema 2.1. Misalkan $B F(5)$ adalah butterfly network 5-dimensi, maka tvs $(B F(5))=39$.

Bukti. Dengan menunjukkan $\operatorname{tvs}(B F(5)) \geq 39$ dan $\operatorname{tvs}(B F(5)) \leq 39$ kita dapat membuktikan teorema diatas. Teorema [6], yaitu $\operatorname{tvs}(G) \geq \operatorname{maks}\left\{\left\lceil\frac{\delta+n_{\delta}}{\delta+1}\right\rceil,\left\lceil\frac{\delta+n_{\delta}+n_{\delta+1}}{\delta+2}\right\rceil, \ldots,\left\lceil\frac{\delta+\sum_{i=\delta}^{\Delta} n_{i}}{\Delta+1}\right\rceil\right\}$.

Derajat minimum dari $B F(5)$ adalah $\delta=2$, banyaknya titik berderajat 2 adalah $n_{2}=64$, derajat maksimum dari $B F(5)$ adalah $\Delta=4$, dan $n_{4}=128$ maka:

$\operatorname{tvs}(B F(5)) \geq \operatorname{maks}\left\{\left\lceil\frac{2+n_{2}}{3}\right\rceil,\left\lceil\frac{2+n_{2}+n_{4}}{5}\right\rceil\right\}=39$. Jadi $\operatorname{tvs}(B F(5)) \geq 39$.

Selanjutnya akan ditunjukkan $\operatorname{tvs}(B F(5)) \leq 39$. Untuk menunjukkan kita harus mengkonstruksi pelabelan-39 total tidak teratur titik $B F(5)$ yang terdapat pada Gambar 2.1. Jadi terbukti $\operatorname{tvs}(B F(5))=39$.

Teorema 2.2. Misalkan $B F(5)$ adalah butterfly network 5-dimensi, maka tes $(B F(5))=108$.

Bukti. Dengan menunjukkan $\operatorname{tvs}(B F(5)) \geq 39$ dan $\operatorname{tvs}(B F(5)) \leq 39$ kita dapat membuktikan teorema diatas. Teorema [2], yaitu tes $(G) \geq\left\lceil\frac{|E|+2}{3}\right\rceil$.

Banyaknya sisi pada butterfly network adalah $r 2^{r+1}=320$ maka:

$\operatorname{tes}(G) \geq\left\lceil\frac{|E|+2}{3}\right\rceil=108$. Jadi $\operatorname{tes}(B F(5)) \geq 108$.

Selanjutnya akan ditunjukkan $\operatorname{tes}(B F(5)) \leq 108$. Untuk menunjukkan kita harus mengkonstruksi pelabelan-108 total tidak teratur sisi $B F(5)$ seperti Gambar 2.2. Jadi terbukti $\operatorname{tes}(B F(5))=108$. 
Edy Saputra, Nurdin, Supri Amir

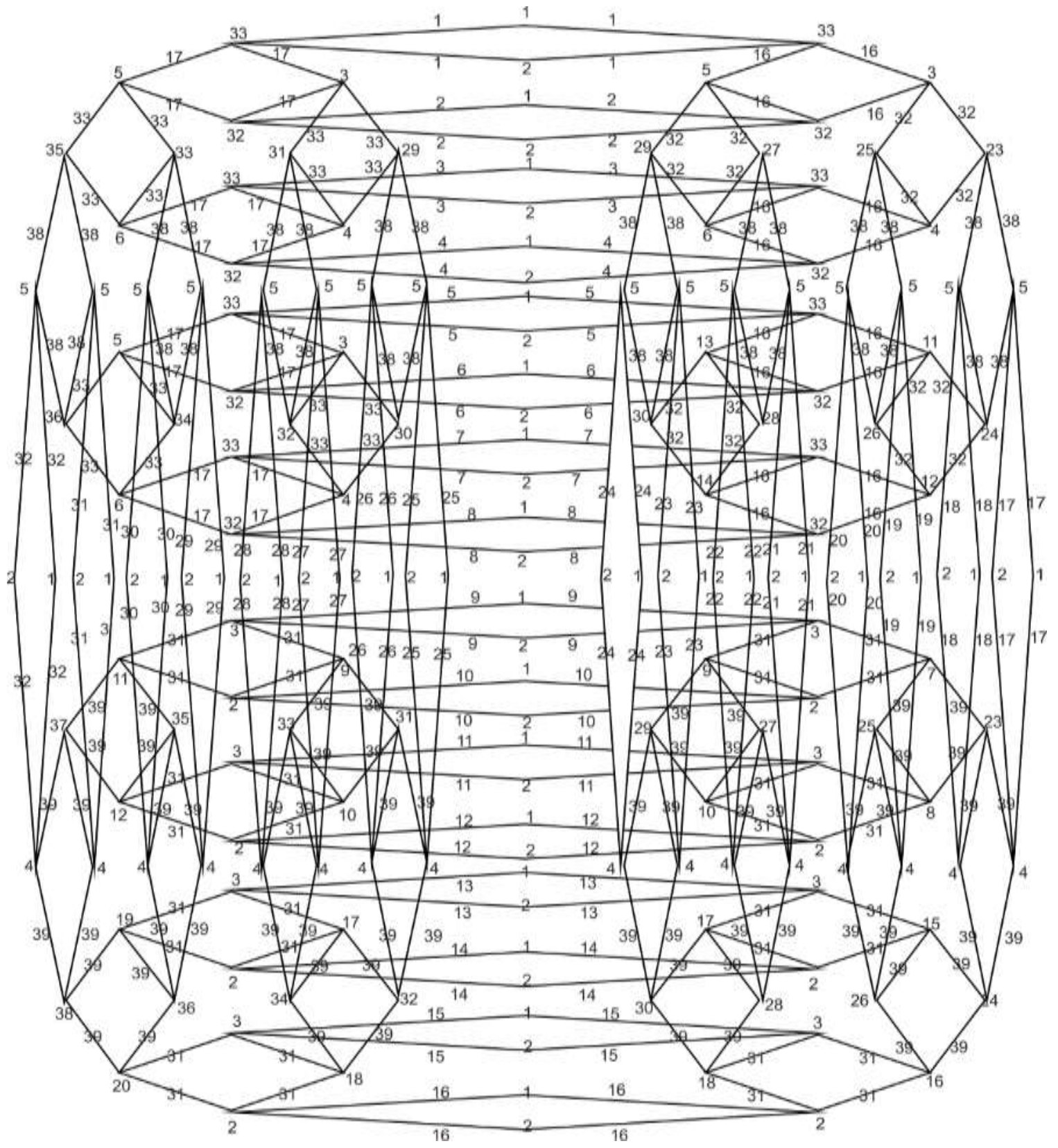

Gambar 2.1 Pelabelan-39 total tidak teratur titik $B F(5)$ 
Edy Saputra, Nurdin, Supri Amir

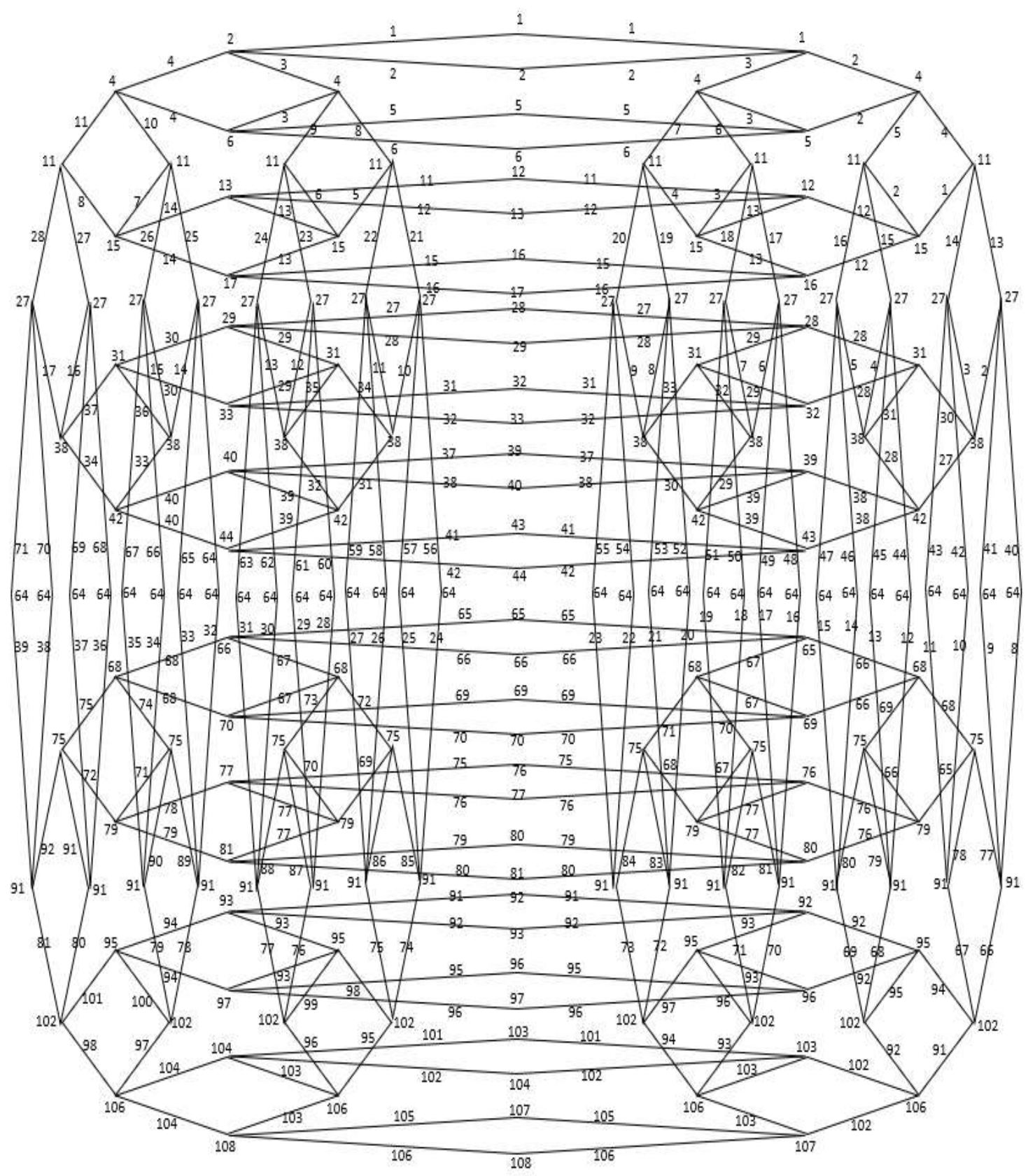

Gambar 2.2 Pelabelan-108 total tidak teratur sisi $B F(5)$ 


\section{Edy Saputra, Nurdin, Supri Amir}

Teorema 2.3. Misalkan BB(5) adalah Beneš network 5-dimensi, maka tvs $(B B(5))=71$.

Bukti. Dengan menunjukkan $\operatorname{tvs}(B B(5)) \geq 71$ dan $\operatorname{tvs}(B B(5)) \leq 71$ kita dapat membuktikan teorema diatas. Teorema [6], yaitu $\operatorname{tvs}(G) \geq \operatorname{maks}\left\{\left\lceil\frac{\delta+n_{\delta}}{\delta+1}\right\rceil,\left\lceil\frac{\delta+n_{\delta}+n_{\delta+1}}{\delta+2}\right\rceil, \ldots,\left\lceil\frac{\delta+\sum_{i=\delta}^{\Delta} n_{i}}{\Delta+1}\right\rceil\right\}$. Jumlah titik berderajat 2 diperoleh dari definisi dimana titik yang berderajat 2 adalah titik yang berada pada level 0 dan $2 r+1$, yaitu $4\left(2^{r-1}\right)=64$. Sedangkan jumlah titik berderajat 4 diperoleh dari selisih jumlah semua titik dengan jumlah titik berderajat 2. $|\Delta(B B(r))|=$ $2^{r}(2 r-1)=288$, maka:

$\operatorname{tvs}(B B(5)) \geq \operatorname{maks}\left\{\left\lceil\frac{2+n_{2}}{3}\right\rceil,\left\lceil\frac{2+n_{2}+n_{4}}{5}\right\rceil\right\}=71$. Jadi $\operatorname{tvs}(B B(5)) \geq 71$.

Selanjutnya akan ditunjukkan $\operatorname{tvs}(B B(5)) \leq 71$. Untuk menunjukkan kita harus mengkonstruksi pelabelan-71 total tidak teratur titik $B B(5)$ pada Gambar 2.3. Jadi terbukti $\operatorname{tvs}(B B(5))=71$.

Teorema 2.4. Misalkan BB(5) adalah Beneš network 5-dimensi, maka tes $(B B(5))=214$.

Bukti. Dengan menunjukkan $\operatorname{tvs}(B B(5)) \geq 214$ dan $\operatorname{tvs}(B B(5)) \leq 214$ kita dapat membuktikan teorema diatas. Teorema [2], dimana tes $(G) \geq\left\lceil\frac{|E|+2}{3}\right\rceil$.

Banyaknya sisi pada Beneš network adalah $r 2^{r+2}=640$ maka:

$\operatorname{tes}(G) \geq\left\lceil\frac{|E|+2}{3}\right\rceil=214$. Jadi $\operatorname{tes}(B B(5)) \geq 214$.

Selanjutnya akan ditunjukkan tes $(B B(5)) \leq 214$. Untuk menunjukkan kita harus mengkonstruksi pelabelan-214 total tidak teratur sisi $B B(5)$ seperti Gambar 2.4. Jadi terbukti $\operatorname{tes}(B F(5))=214$. 


\section{Edy Saputra, Nurdin, Supri Amir}

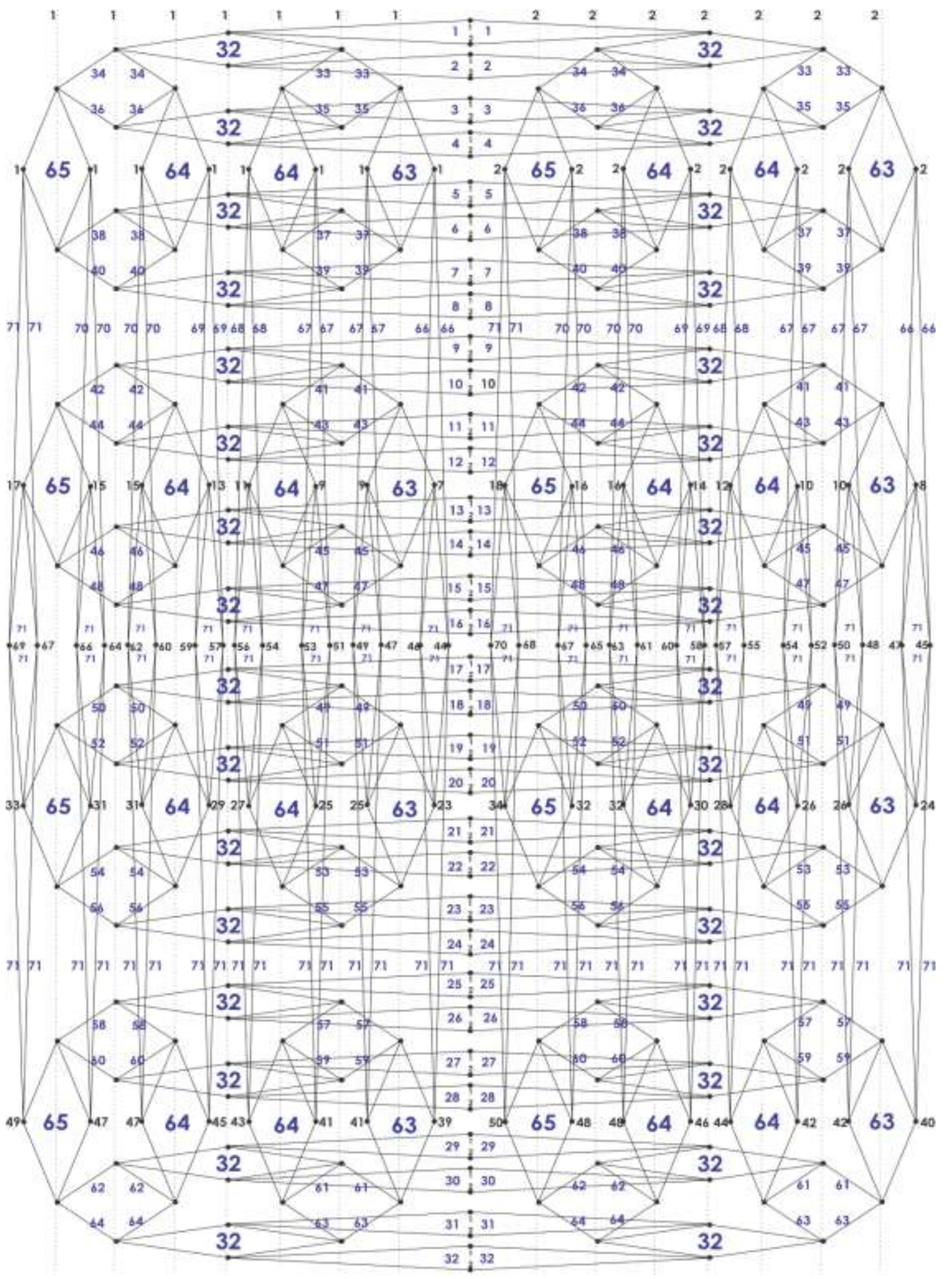

Gambar 2.3 Pelabelan-71 total tidak teratur titik $B B(5)$ 


\section{Edy Saputra, Nurdin, Supri Amir}

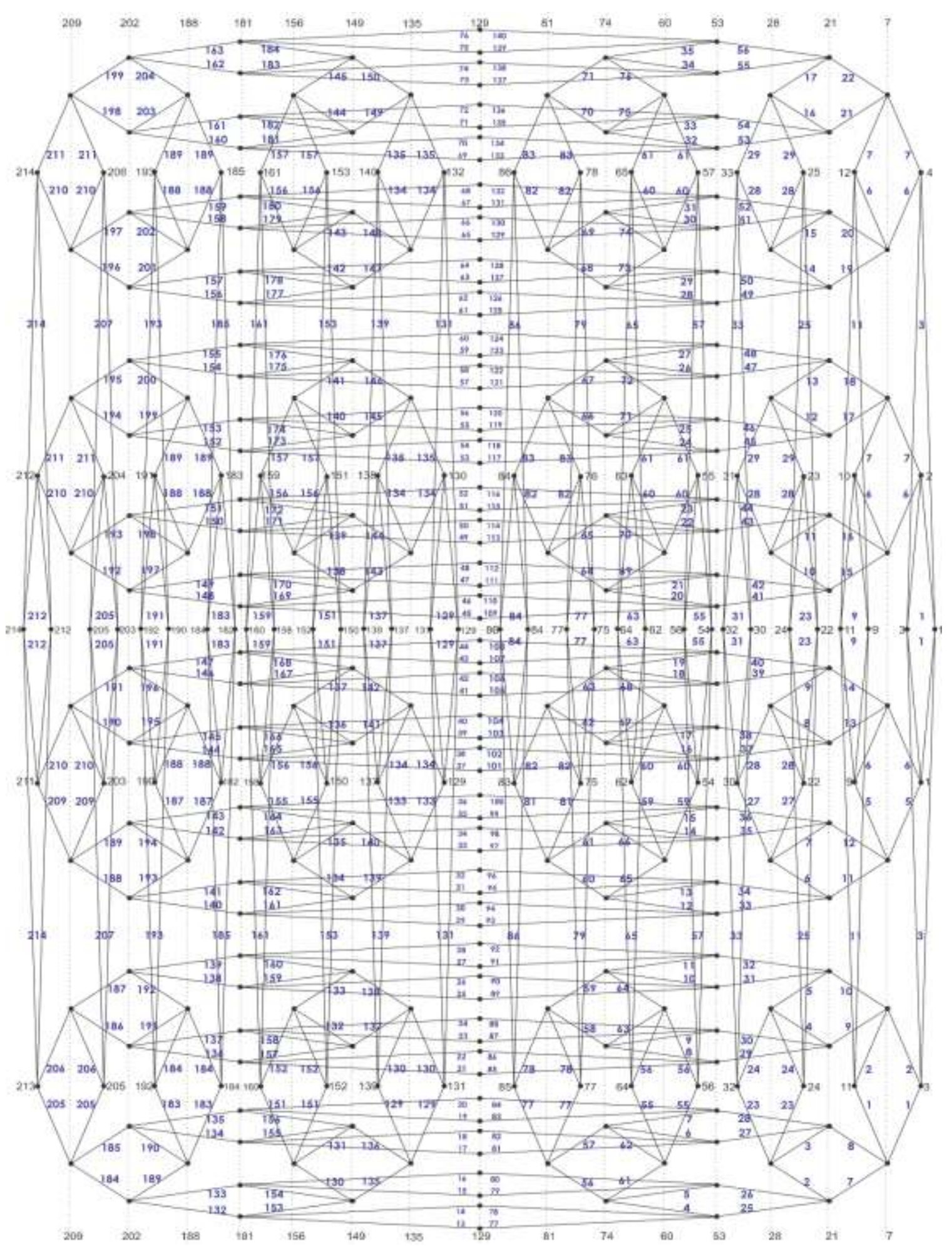

Gambar 2.4 Pelabelan-214 total tidak teratur sisi $B B(5)$ 


\section{Edy Saputra, Nurdin, Supri Amir}

\section{KESIMPULAN}

Berdasarkan Hasil dan Pembahasan diperoleh Nilai total ketidakteraturan titik dan sisi pada butterfly network 5-dimensi yaitu $\operatorname{tvs}(B F(5))=39$ dan $\operatorname{tes}(B B(5))=108$. Untuk Beněs Network nilai total tidak teratur titik adalah $\operatorname{tvs}(B F(5))=71$ dan tes $(B B(5))=214$.

\section{UCAPAN TERIMA KASIH}

Penulis mengucapkan terima kasih kepada Universitas Hasanuddin yang telah membiayai penelitian ini melalui Hibah Internal Penelitian Dosen Pemula (PDPU) tahun anggaran 2020 dengan nomor kontrak 1585/UN4.22/PT.01.03/2020.

\section{REFERENCES}

[1] Ahtsham, S. and Faheem, H. 2019. Vertex Irregular Total Labeling of Grid Graph, Palestine Journal of Mathematics, vol. 8(1): 52-62.

[2] Baca, M., Jendrol, S., Miller, M. and Ryan, J. 2007. On irregular total labellings. Discrete math. 307: 1378-1388.

[3] Chartrand, G. dan Zhang, P. 2005. Introduction to graph Theory. Mc Graw-Hill Press: Boston.

[4] Gallian, J.A. 2019. A Dynamic Survey of Graph Labeling. Electronic Journal of Combinatoric.

[5] Marzuki, C. C., Sari, M., Aryani, F. 2019. Nilai Total Ketakteraturan dari Graf Butterfly Network Level 3. Seminar Nasional Teknologi Informasi, Komunikasi dan Industri (SNTIKI) 11.: 425-432.

[6] Nurdin, Baskoro , E.T., Salman, A.N.M., Gaos , N.N. 2010. On the total vertex irregularity strength of trees. Discrete Mathematics. 310: 3043-3048.

[7] Nurdin. 2017. Total Irregular Labeling of Butterfly Network on Level Two. AIP Conference Proceedings, Vol. 1867(020067): 1-3.

[8] Rajasingh, I., Rajan , B., Arockiamary , S.T. 2011. Irregular Total Labeling of Butterfly and Benes Network. Proceeding Informatics Engineering and Information Science (ICIES). Springer.: 284-293. 